\title{
LOS ESPACIOS INTERMEDIOS Y LA DEFINICIÓN DE UNA ARQUITECTURA REGIONAL.

\author{
UNA BREVE HISTORIA DE LA VIVIENDA Y LA DOMESTICIDAD \\ EN EL SURESTE MEXICANO: MÉRIDA
}

Data recepción: 2013/06/28

Data aceptación: 2014/01/14

Gladys Noemi Arana López

Contacto autora: gladys.arana@gmail.com

\author{
Universidad Autómona de Yucatán
}

\section{RESUMEN}

Se parte del supuesto de que al cambiar la relación entre el ámbito público y el privado, surgieron múltiples elementos arquitectónicos, los cuales conformaron espacios intermedios mismos que coadyuvaron en la transición y definición de las viviendas de la burguesía yucateca hacia finales del siglo XIX y los primeros años del XX.

Considerando como punto inicial de análisis a las viviendas de fines del siglo XIX y principios del XX, se realiza una aproximación crítica comparativa entre aquellos elementos, objetos y ámbitos observados en las viviendas virreinales, para posteriormente analizar a aquellas de la primera mitad y de finales del siglo XX.

Se estudia tanto el papel de los espacios intermedios entre el adentro y el afuera, como los vínculos y articulaciones entre aquellos construidos cercanos a él realizándose una somera aproximación a su significación en los contextos culturales y sociales correspondientes a cada una de las épocas en cuestión.

Palabras clave: vivienda yucateca, espacios intermedios, modernidad arquitectónica

\section{ABSTRACT}

Considering paradigmatic houses built in the late XIXth and early XXth like a virtual starting point and a symmetry axis between the past and the future of yucatecan houses, will be made a critical comparative analysis between those elements seen in the homes of the viceroyalty, and then in the properties of twentieth century.

Also, this paper analyzed the role of the spaces between the inside and the outside, such as links and joints between constructed spaces closest to these, its materiality or constructive conditions and its significance in cultural and social contexts for each of the periods in question.

Keywords: yucatecan housing, in-between spaces, modern architecture

\section{Introducción}

Al ocaso del siglo XIX, la vida en México cobró un sentido hasta entonces desconocido. Apoyado en la filosofía positivista, el presidente de la república Porfirio Díaz, inició una cruzada en pos de la modernización integral de la nación la cual incluyó tanto acciones relacionadas con el equipamiento educativo, el cultural, para la salud y las comunicaciones, como para la producción. ${ }^{1}$ Esta fue una época en donde la región sureste de México y particularmente la zona noreste de la península de Yucatán floreció económicamente, debido en gran medida al aumento en el precio y demanda de la fibra de henequén. $^{2}$

Esta bonanza económica propició que en Mérida, la ciudad capital del estado, se emprendieran sin número de acciones gubernamentales para remontar muchas de sus carencias ancestrales entre las que se encontraban 
aquellas relacionadas con el equipamiento y la infraestructura urbana, ${ }^{3}$ mientras que gran parte de la sociedad con el afán de participar en esta vorágine modernizadora, modificaba el interior de sus viviendas y la fisonomía de sus fachadas o construía nuevas residencias, cuyas propuestas rompieron con las tipologías formales, espaciales y funcionales prevalecientes. ${ }^{4}$

Jardines, escalinatas, pórticos y vestíbulos fueron algunos de los elementos y ámbitos arquitectónicos que empezaron a ser observados y disfrutados por propios y extraños en las viviendas de la burguesía yucateca, sobre todo en el espectacular Paseo de Montejo ${ }^{5}$ el cual se caracterizó por sus aires europeos y por representar un nuevo modo de vida6 (Fig. 1).

Desde la calle permeaban sutilmente a través de los enverjados y cruzando los jardines múltiples imágenes, sonidos y olores, mismos que derivaban en las escaleras que separaban la casa del suelo y se detenían en la pausa impuesta del pórtico o de la terraza, siendo este último el espacio que anunciaba lo que el interior de la residencia resguardaba.
Tomando en cuenta estas generalidades, ${ }^{7}$ se considera que esta temporalidad es la ideal para iniciar el análisis de la constitución moderna de la vivienda de la clase alta yucateca, ya fuera desde la presencia o la ausencia material de las escalinatas exteriores, de la terraza, de los caminos y de los jardines, así como de los vínculos entre los espacios, el mobiliario contenido en ellos y las dinámicas de los usuarios, hasta el lenguaje no explícito de las relaciones entre diversos niveles sociales, las mujeres y los hombres o bien entre los visitantes y los visitados.

Este trabajo parte del supuesto que al cambiar la relación entre el ámbito público y el privado -hacia finales del siglo XIX- entre la calle y las casas, así como entre el adentro y el afuera de estas, surgieron múltiples elementos y espacios que coadyuvaron en la transición y definición de las viviendas y que su surgimiento es un parte aguas en la historia de la arquitectura regional, mismo que paradójicamente puede ser entendido como el punto a partir del cual se construyó la historia de la arquitectura habitacional de la élite yucateca. ${ }^{8}$

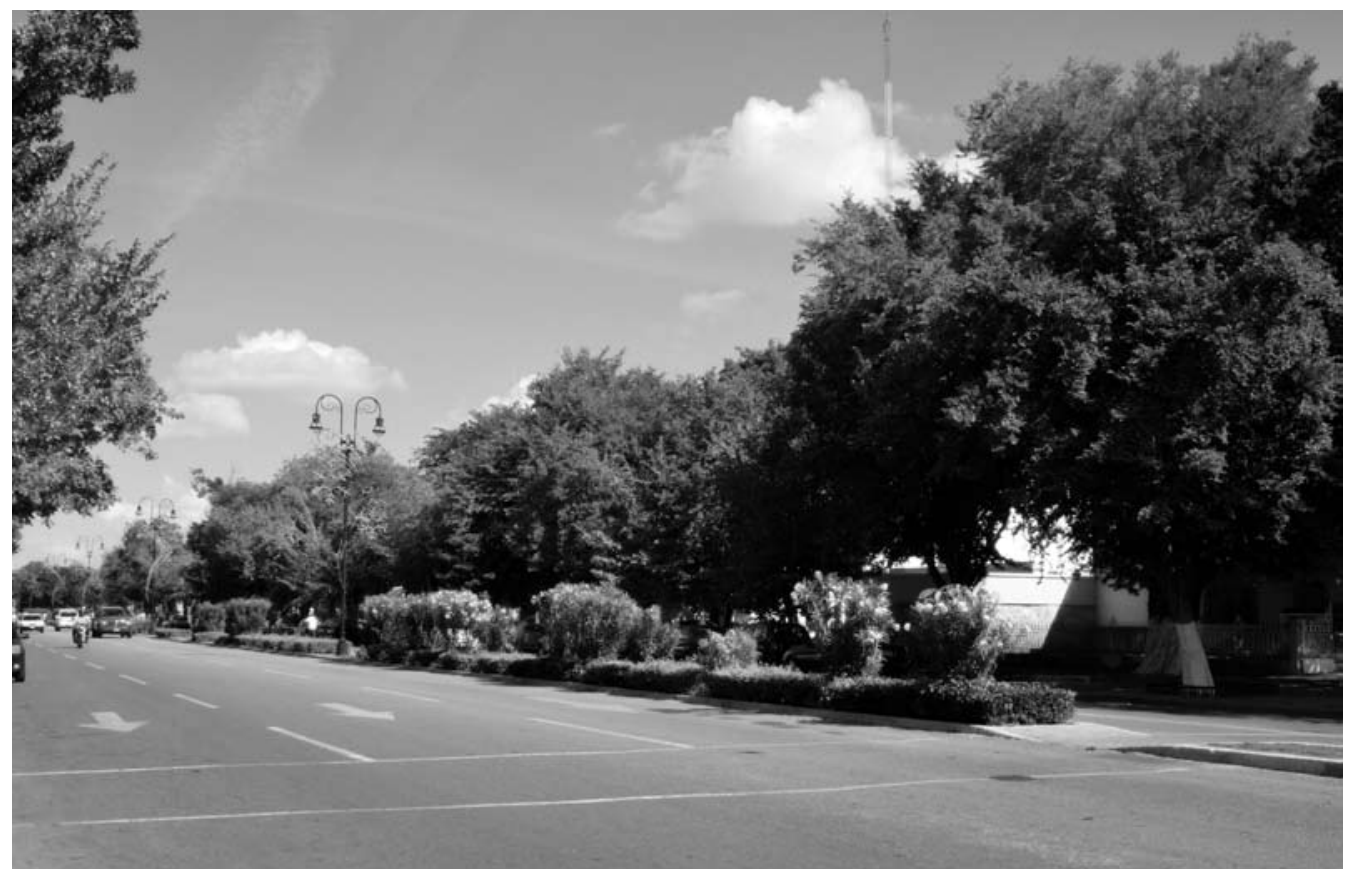

Fig. 1. El Paseo de Montejo en la actualidad. Gladys Arana, Mérida, 2012 
Así pues, el principal interés de este documento radica en el análisis de los elementos arquitectónicos -formales, espaciales y funcionales- concebidos como espacios intermedios, entendidos esencialmente como:

1. los entornos que delimitan lo propio y lo ajeno, así como lo público y lo privado,

2. los ámbitos que posibilitaron la definición contemporánea de los distintos gradientes de intimidad y de actividad tanto interiores como exteriores de la vivienda contemporánea en el sureste mexicano,

3. los lugares en donde las prácticas y deberes socioculturales regionales se adaptaron y apropiaron de las propuestas arquitectónicas externas.

Las temporalidades propuestas son cuatro. Como punto inicial y virtual eje de simetría entre el antes y el después arquitectónico se consideran los espacios intermedios de las viviendas paradigmáticas de fines del siglo XIX y principios del $X X$, se realiza un análisis crítico comparativo entre aquellos observados en estas residencias y los del virreinato, para posteriormente analizar a aquellos de la primera mitad del siglo XX.

La vivienda prehispánica o vernácula -viva hasta nuestro días- se presenta como contexto en el entendido de que en gran medida la relación entre el espacio abierto o público y el cerrado o privado ostenta una condición que a pesar del sinnúmero de hibridaciones, decantaciones e influencias socio-culturales de las cuales ha sido objeto al paso de los años, se conserva e incluso prevalece por encima de las otras mencionadas. Por su parte las casas yucatecas de la actualidad se emplearán exclusivamente para ejemplificar la trascendencia y permanencia de estos elementos cerrando así el ciclo histórico de los espacios intermedios.

En todas estas temporalidades se estudió tanto el papel de estos ámbitos en la definición del adentro y el afuera, como los vínculos y articulaciones entre los espacios construidos cercanos a ellos, su materialidad o condición constructiva y su significación en los contextos culturales y sociales correspondientes a cada una de las épocas en cuestión.
Deriva de dos documentos más extensos. EI primero de estos tuvo como objetivo primario el análisis espacial de las viviendas yucatecas de la clase alta al cambio de siglo. ${ }^{9}$ En el mencionado trabajo se manejó una muestra de 142 viviendas construidas entre los años 1886 y 1916, mismas que fueron caracterizadas a partir de su sembrado en el lote, así como de su organización espacial general, obteniéndose un universo final -conformado por viviendas que podrían ser considerados como arquetípicas- sujeto a ser analizado con mayor profundidad. ${ }^{10} \mathrm{El}$ segundo documento tuvo como objetivo el realizar un análisis comparativo tanto material como espacial y funcional entre las viviendas construidas en el porfirismo y la posrevolución- haciendo énfasis en el hecho de que tanto la permanencia como la transformación de los espacios arquitectónicos en cuestión, se debieron a una serie de circunstancias socioculturales muy particulares. ${ }^{11}$

En gran medida las fuentes de información existentes fueron las que dictaron el sentido de la presente investigación, presentándose la necesidad de abordar el problema tanto cuantitativa como cualitativamente y realizando un estudio comparado transversal. En primer lugar se privilegió el reconocimiento del espacio y el análisis de las plantas arquitectónicas, así como de las imágenes disponibles, las cuales si bien no fueron muchas, posibilitaron la realización de un ejercicio de reconstrucción muy aproximado a la realidad.

Por último, esta labor se justifica ya que si bien en la historiografía nacional existen trabajos de calidad, ${ }^{12}$ en la regional se pueden observar grandes carencias en relación al estudio de los espacios de las viviendas como unidades en continua progresión -e incluso se podría decirse "reinvención"- entendiéndolas como hechos particulares y propios exclusivamente de un momento histórico-arquitectónico en particular.

\section{Lo que había y se quedó. La espacialidad de la vivienda vernácula como antecedente}

La casa vernácula maya actual, es muy parecida -por no decir igual- a aquella que encontraron los españoles a su arribo a estas tierras peninsulares. Las referencias más antiguas sobre 
esta, se remontan al siglo XVI cuando se escribió La relación de las Cosas de Yucatán. ${ }^{13}$

... de la manera (que los indios tenían de) hacer sus casas era cubrirlas de paja, que tienen muy buena y mucha, o con hojas de palma, que es propia para esto; y que tenían muy grandes corrientes para que no se lluevan y que después echan una pared de por medio a todo lo largo, que divide toda la casa, y en esta pared dejan algunas puertas para la mitad que llaman las espaldas de la casa, donde tienen sus camas y la otra mitad blanquean de muy gentil encalado los señores las tienen pintados de muchas galanterías; y esta mitad es el recibimiento y aposento de los huéspedes y no tienen puerta sino toda es abierta conforme a lo largo de la casa y baja mucho la corriente delantera por temor de los soles y aguas, y dicen que también para enseñorearse de los enemigos de la parte de dentro en tiempo de necesidad. El pueblo menudo hacia su costa las casas de los señores; y que con no tener puertas tenían por grave delito hacer mal a casas ajenas. Tenían una puertecilla atrás para el servicio necesario y unas camas de varillas y en- cima una esterilla donde duermen cubiertos por sus mantas de algodón; en verano duermen comúnmente en los encalados con una de aquellas esterillas especialmente los hombres... ${ }^{14}$

Esta vivienda es el resultado de un prolongado proceso de decantación cultural, compuesto por múltiples experiencias acumuladas, que han sido transmitidas de generación en generación. El solar en donde se encuentra ${ }^{15}$ así como el poblado en general puede ser entendido como un todo complejo ${ }^{16}$ y a la vez como resultado de la suma de múltiples microcosmos.

La casa se encuentra constituida por dos módulos simples completamente rodeados de espacios abiertos. El primero de ellos, construido cercano a la calle y paralelo a esta, presenta una planta absidal con una puerta de acceso, misma que se encuentra alineada con otra que comunica con la cocina, conformando un eje de luz y a su vez, dos espacios de oscuridad. Este es un espacio multifuncional por excelencia.

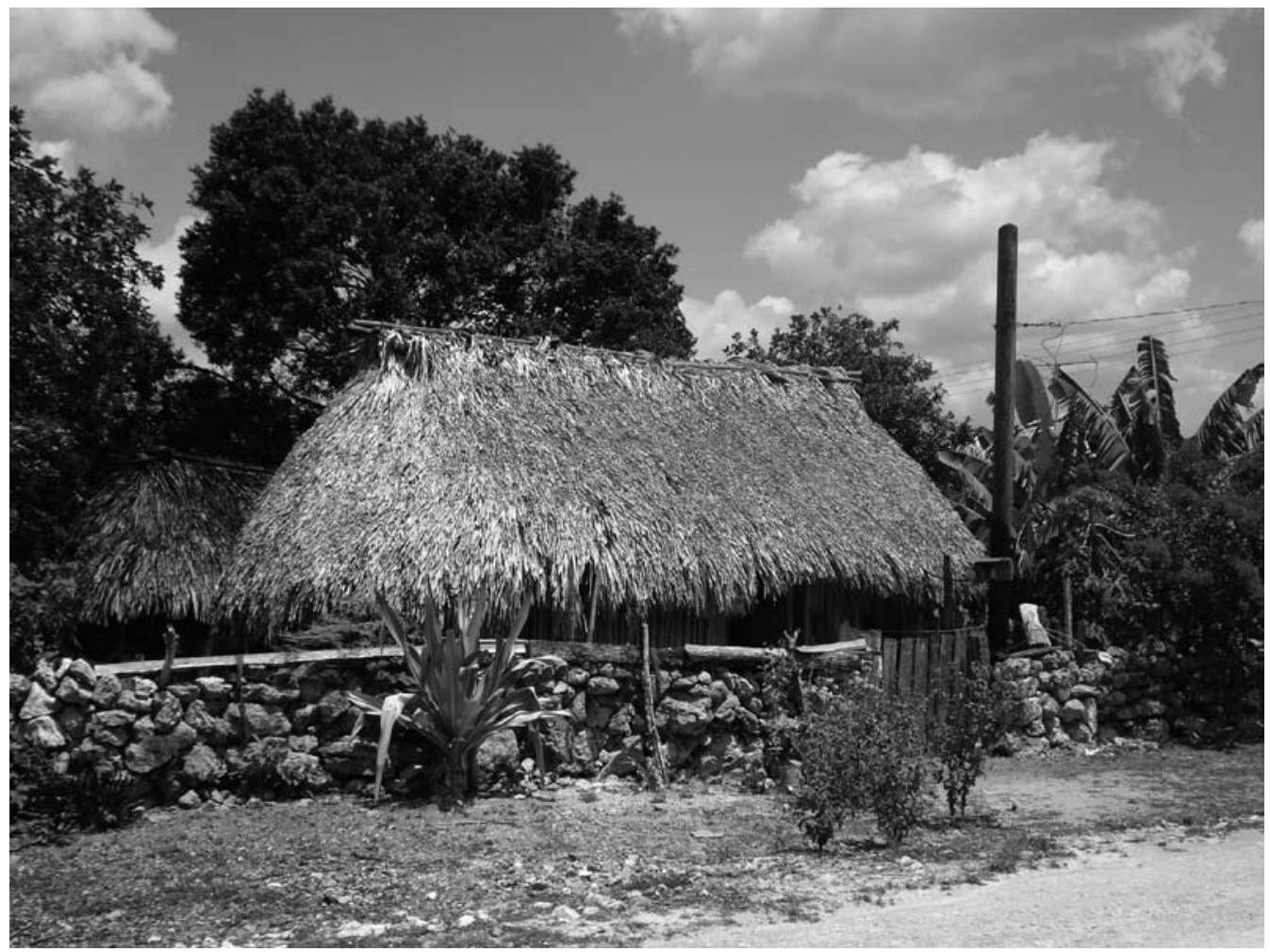

Fig. 2. Vivienda vernácula. Gladys Arana, Yucatán, 2012 
El segundo módulo, más pequeño y semiabierto, es en donde se cocina y se vive la tradición cotidiana de la ingesta de los alimentos. Es también el espacio de reunión de las mujeres de la familia sobre todo cuando preparan los festines para las celebraciones de la comunidad.

Sin embargo, el espacio esencial para el desarrollo de la vida cotidiana, es el abierto semipúblico que rodea toda la vivienda y que caracteriza el ámbito rural. En este se realizan todas aquellas acciones complementarias del habitar y aunque originalmente, era considerado como una unidad territorial de grandes proporciones, también fue entendido como una entidad funcional integral, en donde se realizan actividades que van desde la convivencia social a la cría de animales.

Las viviendas se encuentran organizadas a lo largo de las calles y remetidas del paramento, por lo que el espacio social está al frente de esta, delimitado por dos grandes piedras o bancas flanqueando la entrada a la propiedad en donde aprovechando el fresco de la tarde se realizan las tertulias informales, mientras que las miradas de propios y extraños se filtran por medio de hileras de macetas con plantas de ornato, medicinales o para la comida (Fig. 2).

En el impasse temporal entre la llegada de los españoles hasta que edificaron sus primeras viviendas permanentes, estos habitaron grandes casas de paja construidas según los naturales del lugar, satisfaciendo su necesidad de cobijo a la vez que procuraban paulatinamente adaptarse a las condiciones climáticas del entorno, sin embargo, con la construcción de las nuevas residencias permanentes, la implementación de elementos arquitectónicos derivados de sus localidades ibéricas prevalecieron sobre aquellas que encontraron en la región peninsular novohispana. Algunos elementos como la vegetación y la permeabilidad permanecían retornando así a la esencia arquitectónica espacial regional.

\section{Hacia el pasado. Del siglo XIX al XVI}

Hasta las últimas décadas del siglo XIX, la imagen de la ciudad era aquella construida o derivada directamente de las propuestas arqui- tectónicas virreinales, con un patrón arquitectónico completamente introvertido y en donde las actividades cotidianas tenían efecto detrás de gruesos muros. Las nuevas viviendas construidas en el ocaso del siglo XIX, más allá de las modificaciones formales, invirtieron sus partidos arquitectónicos estableciendo una dialéctica muy particular y novedosa entre la ciudad y el hogar, el interior y el exterior, así como entre el espacio público y privado, de tal manera que se definió su distribución de acuerdo con los usos cotidianos de la modernidad. ${ }^{17}$

Poco a poco la tipología habitacional de patio central y vivienda en cinta $^{18}$ fue sustituida por nuevas casas de la alta sociedad, construidas alejadas de la calle, separadas de sus linderos y con desplante central, cumpliéndose con ello algunos de los que quizás fueron sus objetivos primarios: dividir y filtrar el espacio existente entre la calle y la casa, intermediar entre el entorno público y el privado, indicar las circulaciones exteriores -mismas que continuaban en el interior de las casas- señalar los límites de propiedad, así como los diferentes entornos medio ambientales, delimitando simbólicamente lo propio y lo ajeno, lo mundano y/o común, así como lo privilegiado o único.

Los elementos que definieron esta intermediación fueron tanto físicos como simbólicos, considerándoseles particulares y especiales, debido quizás a la época en la cual hicieron su aparición en el medio yucateco. Entre estos se encontraban las rejas de hierro, los jardines delanteros, los pórticos o vestíbulos y las terrazas. Y es que muy probablemente, por la localización y distribución de las nuevas viviendas en sus terrenos, la pertinencia de la reja como elemento de control de la propiedad fue incuestionable al surgir en sustitución de los pesados muros ${ }^{19}$ que conformaban el paramento de las calles yucatecas construidas entre el siglo XVI y las primeras décadas del XIX, de tal manera que la herrería como elemento de seguridad se trasladó hacia el límite de lo propio, por lo que los barrotes de hierro abandonaron los vanos de las ventanas y los postigos, para reconstituirse al margen de la calle. $^{20}$

Las rejas permitían las fugas visuales bidireccionalmente compensando virtualmente lo redu- 


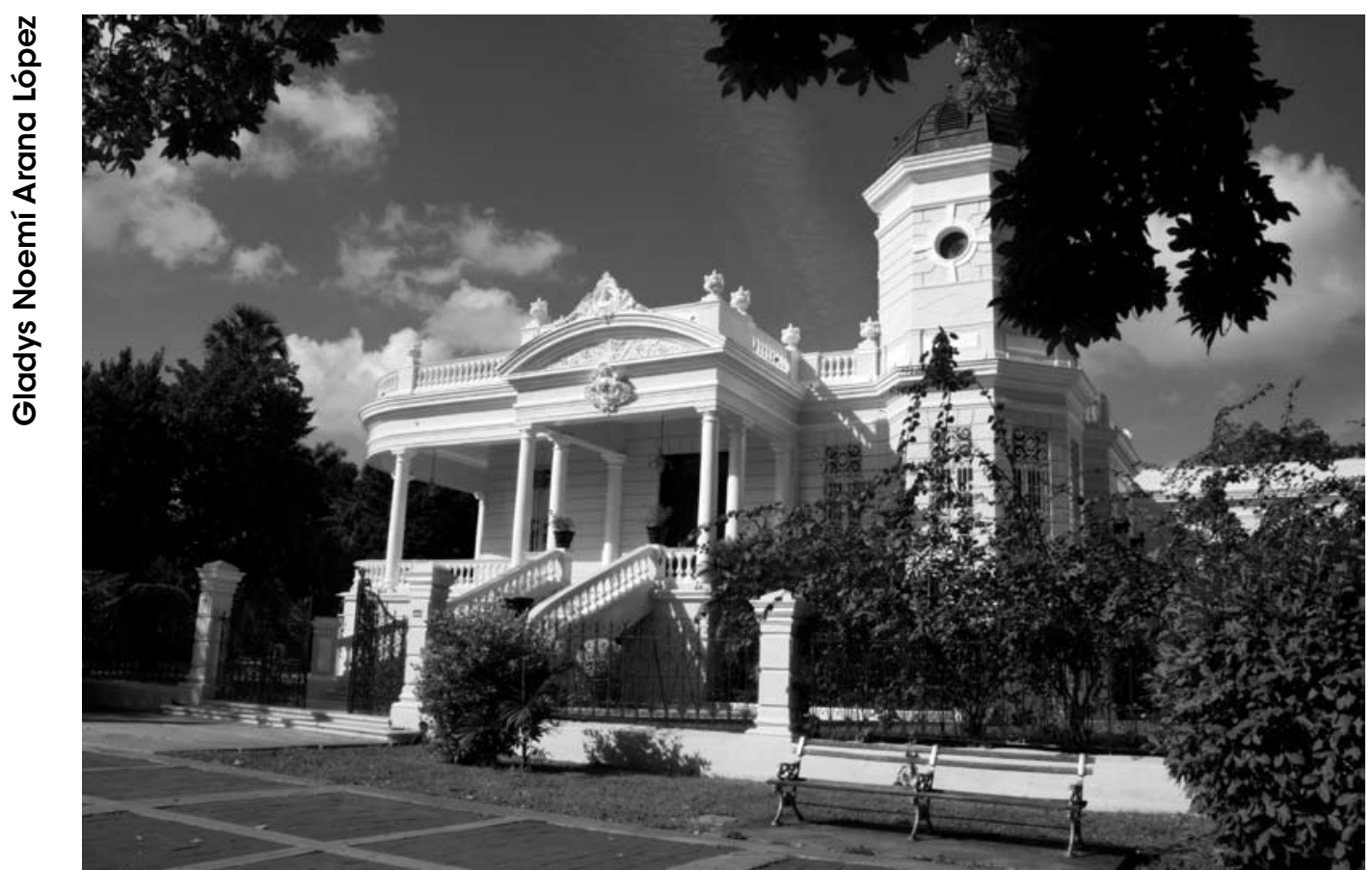

Fig. 3. Vivienda porfiriana con jardín y rejas delanteras. Gladys Arana, Mérida, 2011

cido del lote y posibilitando que las edificaciones se percibieran dentro de un contexto más grande. La vida de las calles permeaba lentamente a través de ellas y con sus detalles, adornaban, bordeaban, marcaban y enfatizaban los límites de las propiedades revelando las bellezas que se encontraban en el jardín inmediato. La casa, como símbolo de status social, podía ser admirada, más no se podía tener acceso a ella (Fig. 3).

El jardín cobró importancia como elemento de recogimiento y protección del exterior, sus múltiples variantes trataban de recuperar gran parte de la calidad de vida pretérita e intentaban emular las condiciones habitacionales de las viviendas campestres. También fue resultado del carácter, de la cultura y de un gusto muy particular no sólo del creador, sino de quien lo iba a disfrutar, de quien lo atendía y mantenía. ${ }^{21}$

Estos jardines se podían ver a través de las rejas y fueron creados para amortiguar el bullicio de la calle, para satisfacer las exigencias higiénicas y recreativas del positivismo, al tiempo que se distraían las miradas indeseables de los cu- riosos y permitían la percepción de la grandeza de la vivienda y con ello la importancia de sus moradores, pero prevaleciendo la conciencia de que la fluidez y el intercambio entre el adentro y el afuera se entendían como sinónimos de vida y posibilidad de transformación. El espacio contenido se volvió contenedor o envolvente.

No hay que olvidar que para entonces la concepción de jardín era muy diferente a la del patio que anteriormente se encontraba en el centro de las viviendas. El patio como concepto de espacio delimitado por edificaciones, era uno de los elementos arquitectónicos de influencia europea que más arraigo había tenido en las viviendas que se produjeron en Mérida. El patio español fue adquiriendo más presencia dentro del esquema de estas, muy probablemente debido a las condiciones ambientales que hacían que su función inicial propiamente de corral, sufriera modificaciones, hasta llegar a ser el elemento proveedor de un microclima interno.

Trasponiendo las grandes rejas que delimitaban el ámbito público del privado, los caminos 

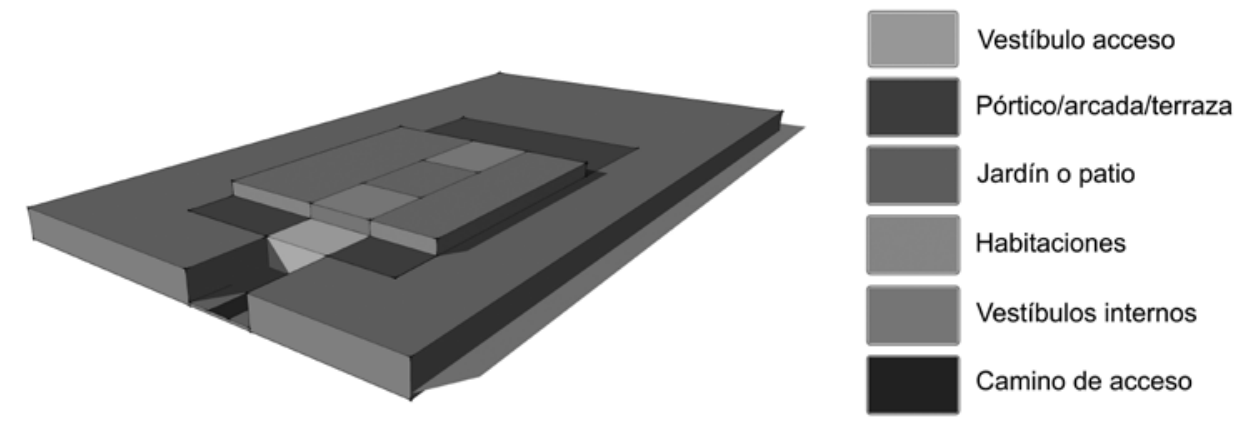

Fig. 4. Esquema señalando los espacios intermedios de una vivienda porfirista. Gladys Arana, Mérida, 2013

de acceso a la vivienda sobriamente vinculaban la calle con la casa, marcando un eje de composición y de direccionalidad, señalando el punto más importante del conjunto y dominando simbólicamente al visitante, ya que su disposición ayudaba a definir la primera impresión de toda la propiedad.

Al final de ese camino se encontraba la casa, misma que estaba desplantada del suelo, lo que implicaba encontrarse con escaleras que ascendían hasta el acceso principal. Esta escalinata estaba bordeada por balaustradas y construidas en mármol y tenían elegantes pasamanos que remataban con copones o maceteros. Al término de la escalera, la transición entre el interior y el exterior se daban mediante un pórtico que vinculaba funcionalmente tres espacios: por un lado la escalera, en el interior el vestíbulo y lateralmente la terraza. Regularmente estaba enmarcado por columnas de fuste circular, texturizas y rematadas con ostentosos capiteles, al centro se localizaba un dintel con el monograma de la familia, reivindicando el ser y tener de la sociedad porfirista.

Los pórticos fueron muy ricos en sus manifestaciones formales y en sus relaciones espaciales, proveían de espacios espontáneos para el descanso complementándose con las terrazas. Estas fueron exactamente la contrapropuesta de la arcada interior que existía en las viviendas virreinales, compuestas por siete o nueve arcos, regularmente de medio punto.
Por otra parte, definiendo un límite no explícito estaba el pórtico, ámbito en donde se llevaba a cabo el rito del saludo inicial y el de despedida, mientras que el vestíbulo a manera de transepto ordenaba y articulaba la casa en relación a sus gradientes de intimidad y zonas funcionales, enfatizaba el eje de composición de la vivienda y debido a su ubicación estratégica marcaba los recorridos a desarrollarse por la servidumbre, por los propietarios de la casa y por los visitantes, al tiempo que condicionaba la dirección de las miradas de propios y extraños (Fig. 4).

Este último espacio derivó del zaguán, mismo que era el elemento de transición entre el ámbito público y el privado. ${ }^{22}$ Era la primer área con la cual se tenía contacto al acceder a la vivienda -ya fuera en vehículo de tracción animal o a pie- y servía de vestíbulo al patio central. Se localizaba dentro del esquema general de la planta, abriéndose al exterior con un portón de madera con postigos de remates conopiales y coronado por una gran portada de piedra (Fig. 5).

$Y$ es que si bien el esquema de organización que prevalecía era en " $L$ " este al ser situado dentro de un conjunto tendía a ser delimitado a manera de un patio central definido con elementos arquitectónicos secundarios o auxiliares tales como cercas, bardas, portadas y vegetación. Este ámbito central adquirió un rol relevante hacia finales del siglo XVIII e inicio del XIX cuando se empezó a decorar y se le añadieron pórticos en dos o tres de sus lados con arcos y columnas de diversos órdenes. ${ }^{23}$ 


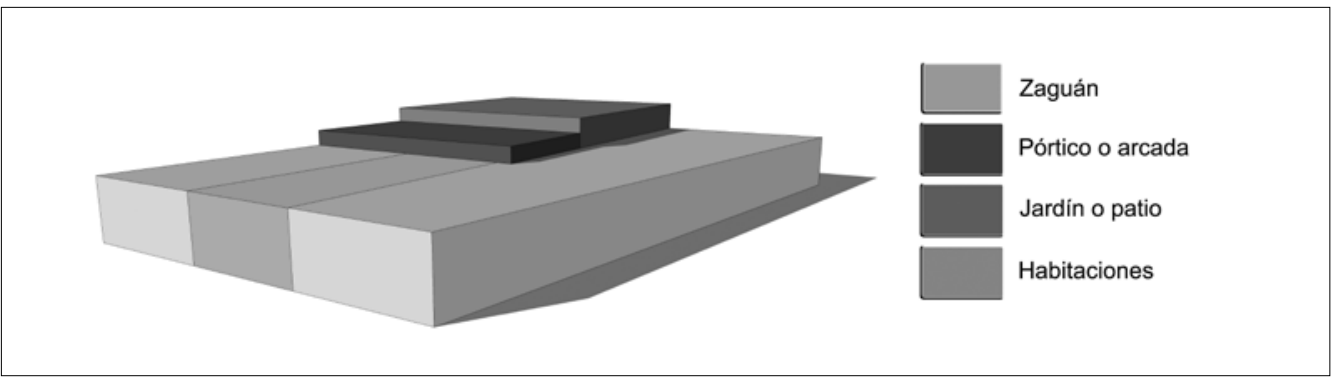

Fig. 5. Esquema señalando los espacios intermedios de una vivienda virreinal. Gladys Arana, Mérida, 2013

Del porfirismo a la posrevolución. Los años 1930's

A los pocos años de haber iniciado el siglo $\mathrm{XX}$, inició un movimiento armado conocido como Revolución Mexicana, generándose cambios en los modelos cultural, político y económico porfirianos, lo que junto con el desarrollo tecnológico generó la modificación de las propuestas espaciales y funcionales características de esta nueva época. Realmente los ámbitos arquitectónicos intermedios de las viviendas posre- volucionarias de la élite no presentaron grandes cambios en relación a sus predecesoras, ${ }^{24}$ muy probablemente esta permanencia se debió a:

1. la aparente lejanía que tuvo la región con el movimiento armado, propició que se conservara la inercia modernizadora iniciada en el porfirismo y consecuentemente en el uso de los lenguajes arquitectónicos empleados en ellas,

2. la intención de la sociedad yucateca de señalar su pertenencia o bien su perma-

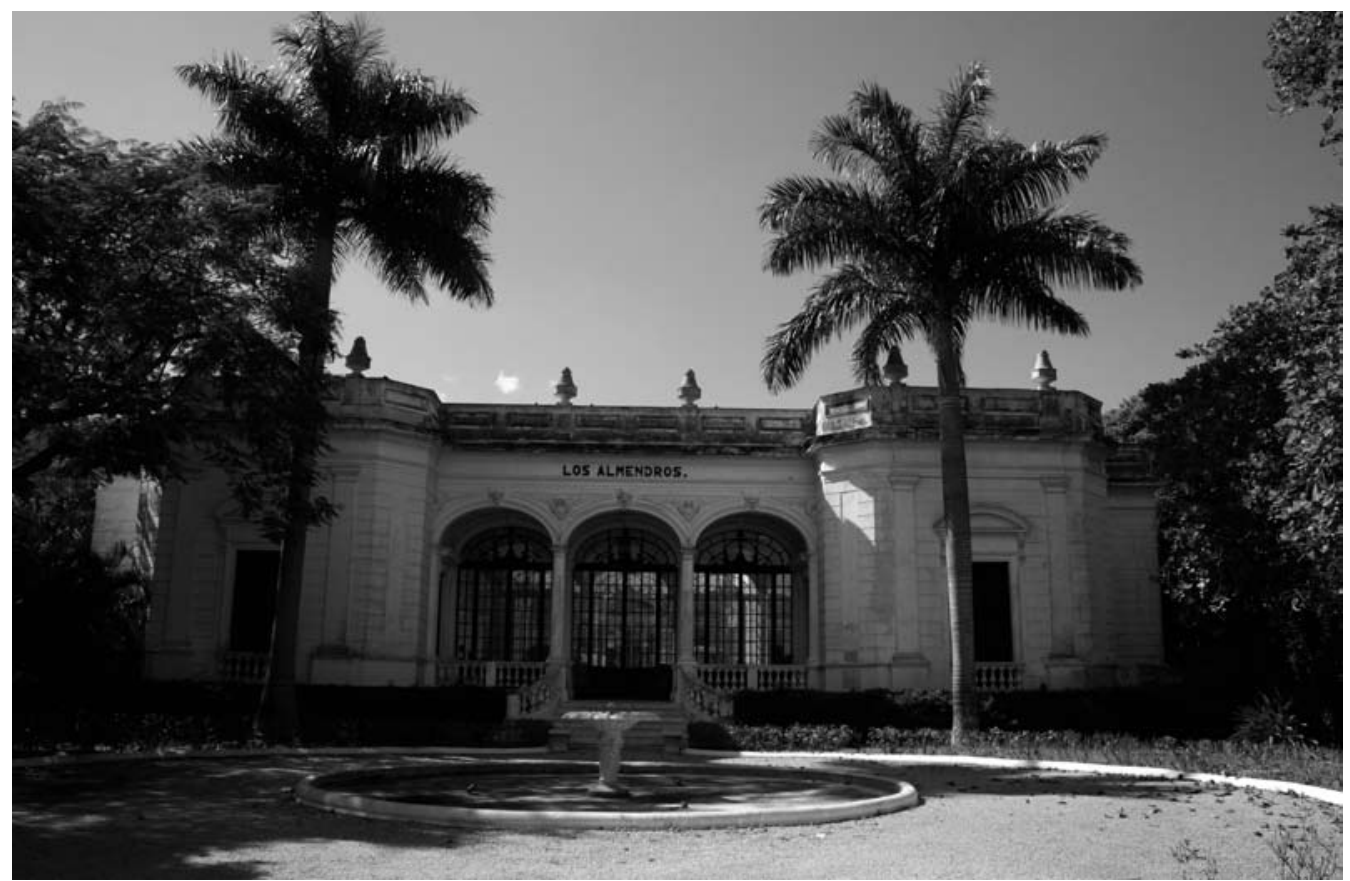

Fig. 6. Vivienda posrevolucionaria. Gladys Arana, Mérida, 2011 


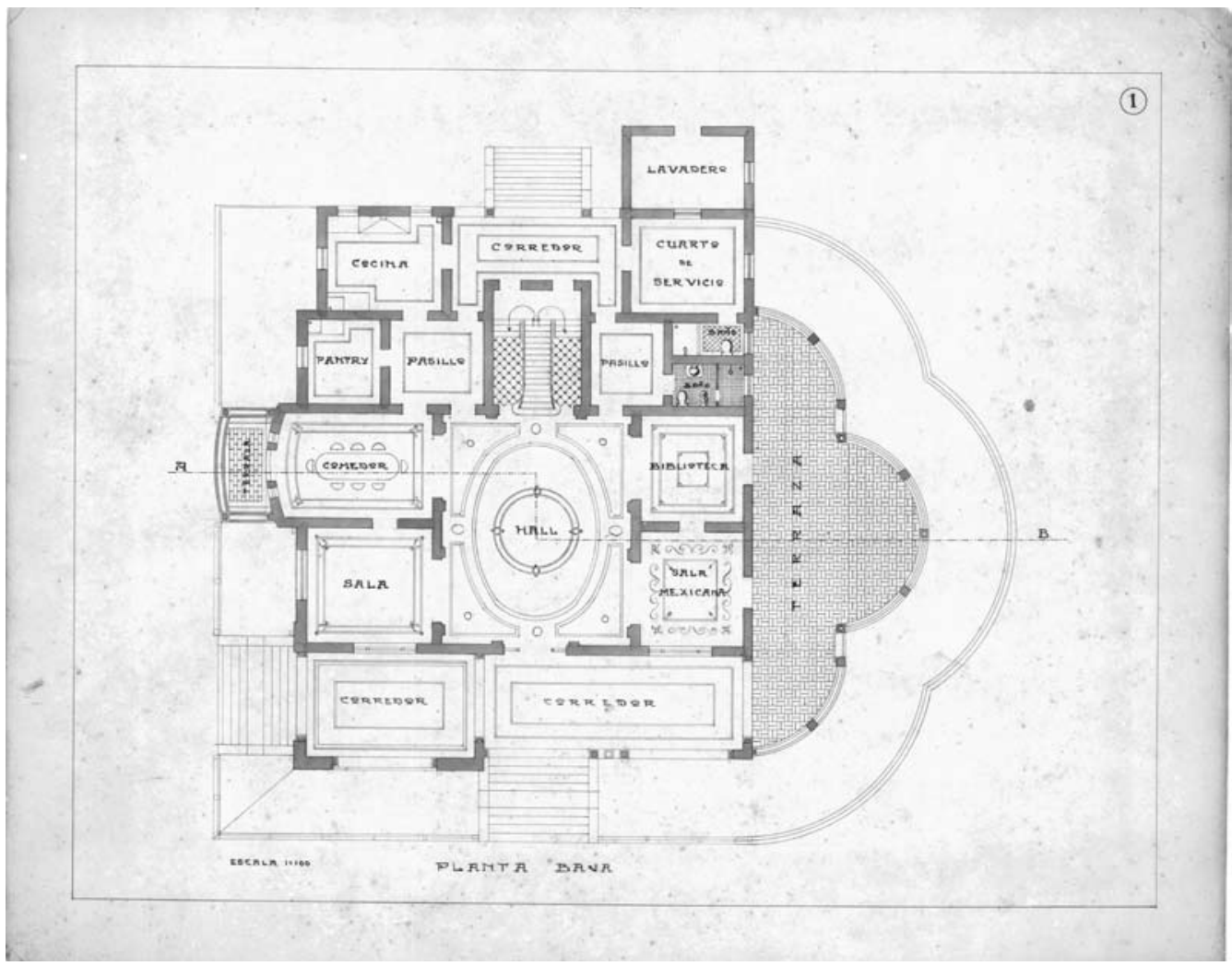

Fig. 7. Plano de vivienda posrevolucionaria. Archivo personal Gladys Arana, Mérida, 1938

nencia aún ante su nueva conformación social, y por ello se hacía referencia al pasado próximo, mismo que se encontraba directamente relacionado con las glorias económicas y políticas,

3. la necesidad de expresar su valor social, sacando parte de su vida al exterior de las viviendas (Fig. 6).

La modernización de las viviendas se expresó tanto en sus propuestas formales, como en las reconfiguraciones funcionales y en la definición integral de los espacios. ${ }^{25}$ Sin ser ya ninguna novedad, desde la calle se podían ver los jardines a través de los enverjados. Las rejas, ${ }^{26}$ más que guardianes de la intimidad eran entendidas como indicadores de los límites materiales de la propiedad, mientras el jardín era una extensa área con césped o con una que otra planta de ornato dispuestos en la periferia de la masa edificada de la casa. ${ }^{27}$
Las escaleras de acceso que desplantaban a la vivienda -solo un metro sobre el nivel de la calle aproximadamente- tampoco eran más aquel elemento de representación y dominio que ejercía el propietario de la residencia sobre aquel que osaba invadir su intimidad y el pórtico más que un espacio de resguardo y espera, explícitamente se convirtió en continuidad del espacio social, siendo las terrazas complemento tanto de él, como del jardín ${ }^{28}$ (Fig. 7).

El vestíbulo y el hall se definieron individualmente, siendo este último el gran espacio de representación social. En él se encontraban las escaleras que derivaban en el área íntima, las cuales habían reforzado su papel protagónico en la organización de la casa, ya que además de ser un espacio de representación fortalecido, también era un elemento escultórico y de vinculación espacial, conjuntando las posibilidades de traslado con la belleza (Fig. 8). 


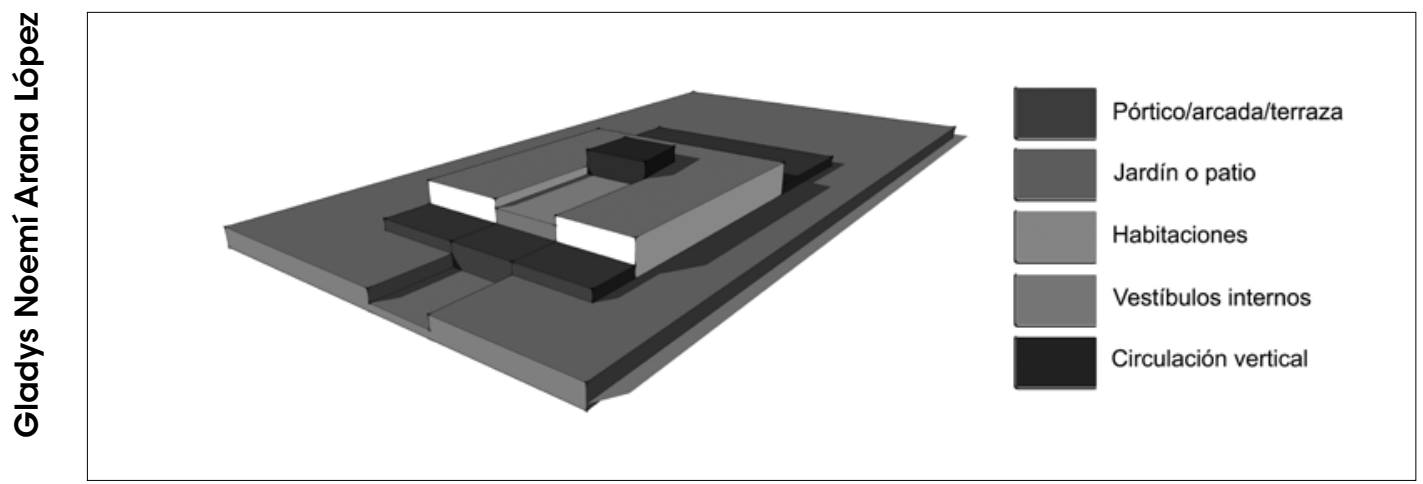

Fig. 8. Esquema señalando los espacios intermedios de una vivienda posrevolucionaria. Gladys Arana, Mérida, 2013

\section{LA MODERNIDAD DE LOS AÑOS 1950'S}

A partir de los años 1950, la ciudad cambió su imagen urbana de nuevo. Su crecimiento se dio hacia el norte y ahí se construyeron infinidad de viviendas, mientras que su parte consolidada mantuvo la imagen colonial y decimonónica derivada de modernizaciones previas.

Debido en parte a las tendencias en el diseño que prevalecían en el orbe, así como por la formación profesional en el extranjero de los arquitectos que en aquel entonces dominaban la escena de la arquitectura regional, muchos de los planteamientos formales y funcionales observados en las nuevas edificaciones derivaban de la escuela internacional de diseño. Sin embargo, las propuestas espaciales rompieron con todos los paradigmas, ya que los conceptos traídos de otras partes del mundo se adaptaron, sobre todo para satisfacer las demandas medioambientales de la región, condicionando a los que se ha denominado como ámbitos o espacios interme$\operatorname{dios}^{29}$ (Fig. 9).

Así, las rejas hacia la calle desaparecieron abruptamente y el jardín magnificado fue entonces el primer punto de contacto y filtro entre la calle y la casa. Quizás esto se debió a que muchas de las viviendas presentaban un programa arquitectónico en donde tanto el área social como la privada estaban en un segundo nivel, mientras que los servicios se encontraban en la planta baja. También se privilegiaron dos tipos de jardines, el primero, derivado directamente de los decimonónicos, totalmente plano, con césped y plantas ornamentales y el otro con grandes taludes e incorporando parte de la vegetación original del lote, generando con ello un sentido de integración entre el elemento construido y el medio natural.

Los caminos se reconfiguraron, dejando de ser direccionales y consecuentemente perdieron su papel de elementos o ámbito intermedios. Ahora eran más que nada andadores sinuosos e integrados a otros de mayores dimensiones por donde circulaban los vehículos en camino hacia la cochera, mientras que las escaleras eran más escultóricas que funcionales debido a su trazo condicionado por el jardín, el cual las abrazaba forzando su integración (Fig. 10).

El pórtico como espacio intermedio se mantuvo aunque su presencia formal se volvió difusa al integrarse totalmente a la terraza delantera, mientras que el vestíbulo interior, ya no tenía una relación estrecha con el mencionado espacio, consolidándose la posición que había adquirido en los años de la posrevolución como parte fundamental del ámbito social.

\section{Conclusiones}

Durante las últimas dos décadas del siglo XIX y la primera del XX, la élite yucateca, consolidó la materialización de la modernidad en sus casas, rompiendo con los modelos arquitectónicos prevalecientes desde el virreinato con una madurez simbólica y funcional cuya concepción espacial y formal perduraría y afianzándose en la 


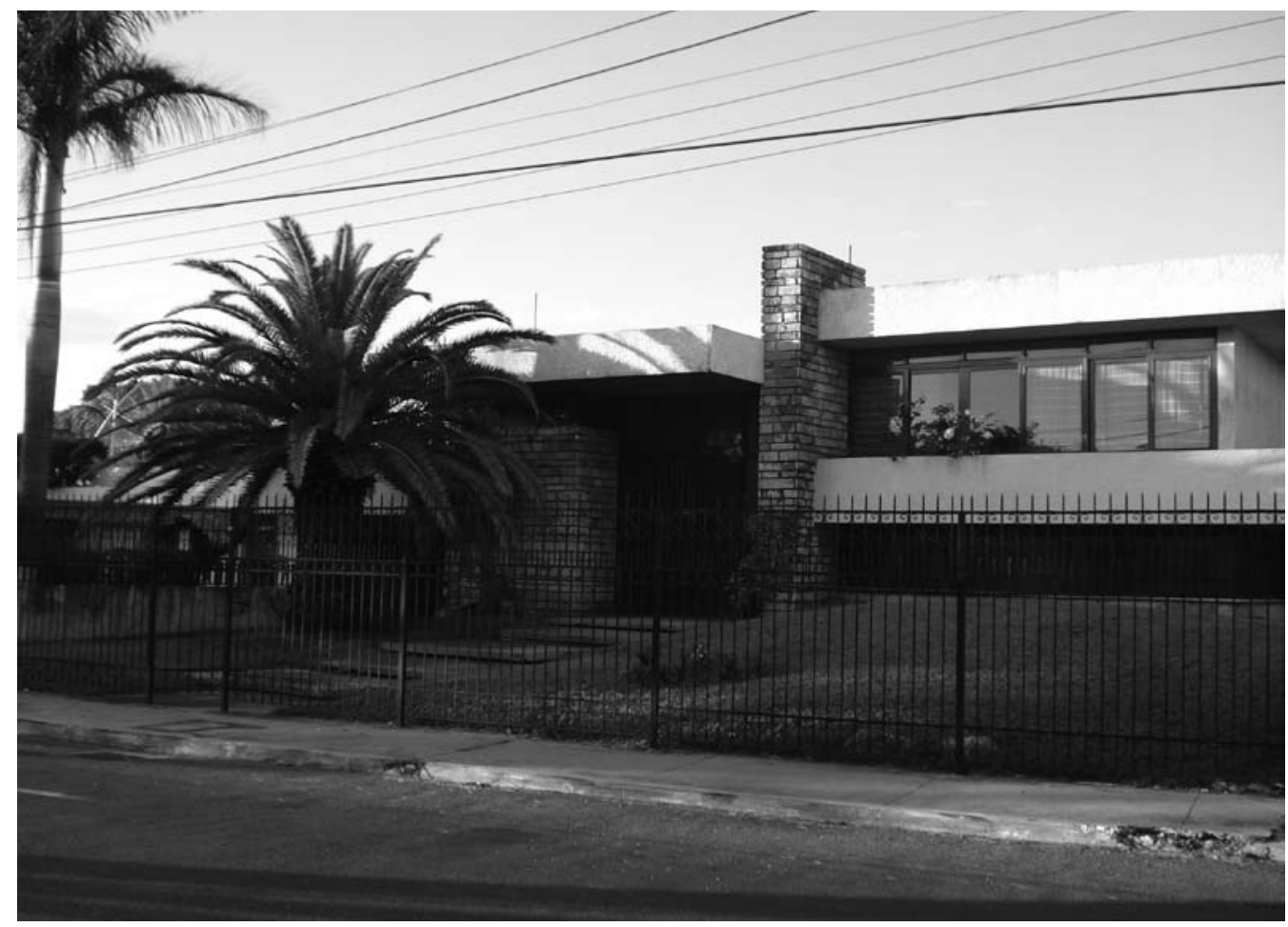

Fig. 9. Vivienda moderna. Gladys Arana, Mérida, 2011

memoria volviéndose parte del imaginario colectivo regional.

La casa se fortaleció como el sitio de la vida privada, por lo que poniendo distancia por medio, las rejas y los jardines demarcaron la propiedad y el ámbito individual consolidando el concepto de distancia-límite y si bien se debilitó la relación entre la calle y la casa, el vínculo entre interior y exterior nunca había sido tan equilibrado, empleando para ello elementos de un lenguaje que simbólicamente expresaba orden, protección y representación. Al paso del tiempo, estos planteamientos espaciales se fortalecieron y estuvieron presentes en el lenguaje de las viviendas de la renovada élite yucateca posrevolucionaria, así como en aquellas residencias de la modernidad funcionalista.

En la actualidad se percibe una hibridación tipológica-temporal en la definición de los espacios o elementos intermedios. Las casas se
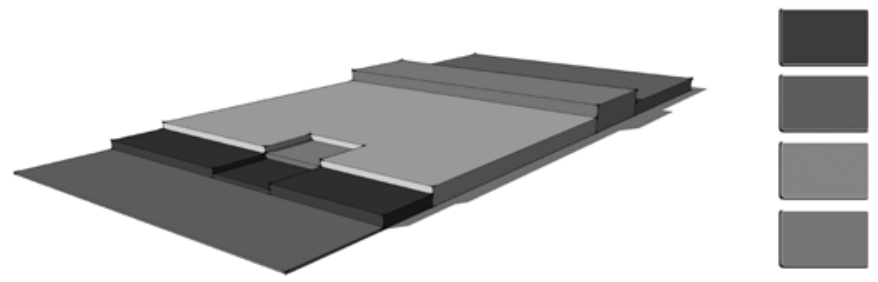

Pórtico/arcada/terraza

Jardin o patio

Habitaciones

Vestibulos internos/traseros

Fig. 10. Esquema señalando los espacios intermedios de una vivienda moderna. Gladys Arana, Mérida, 2013 


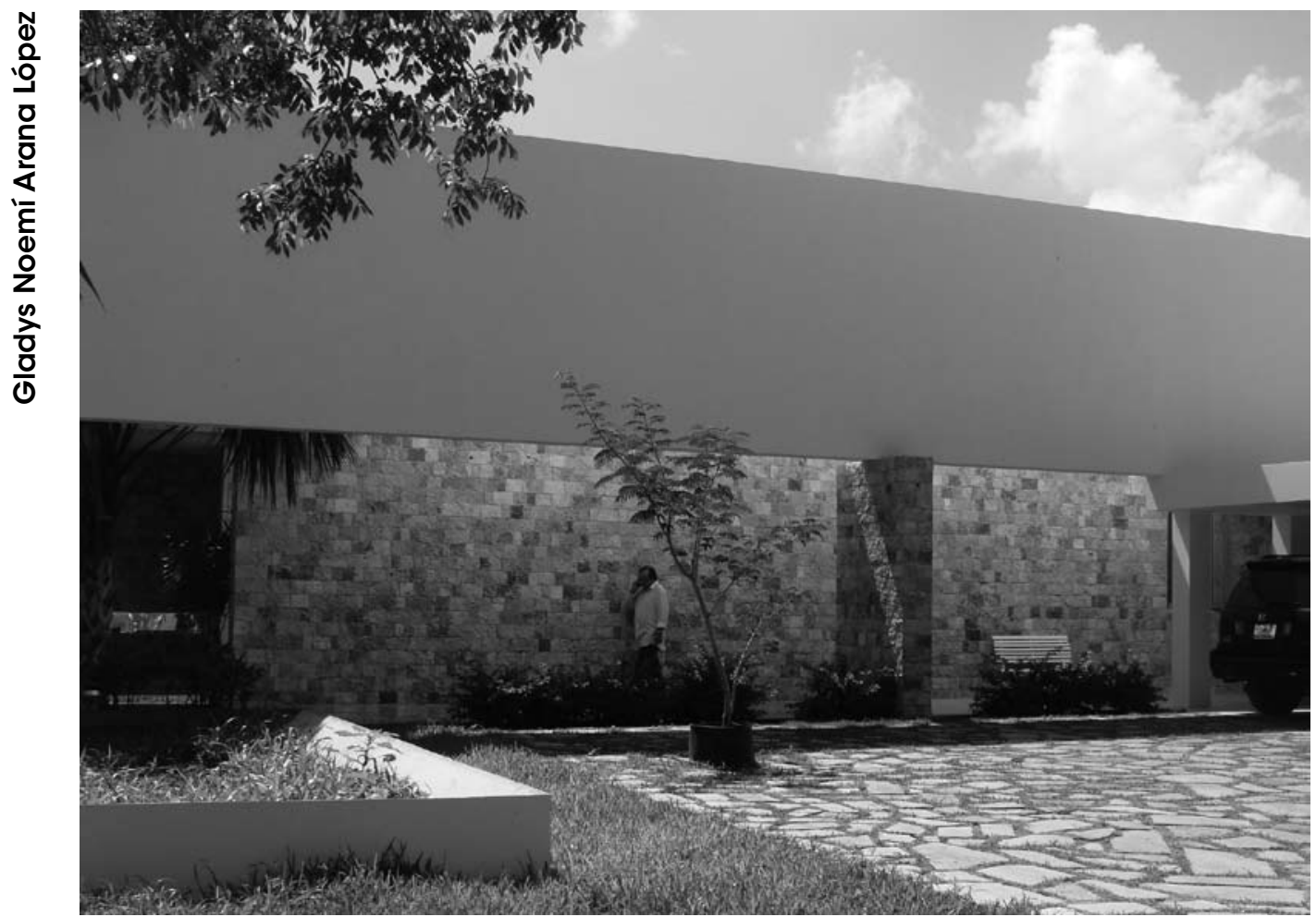

Fig. 11. Vivienda contemporánea yucateca. Gladys Arana, Mérida, 2012

encuentran cerradas completamente hacia el exterior, pero en el interior del lote, el jardín, los caminos, los pórticos, las terrazas y los vestíbulos permanecen, privilegiando el sentido abstracto definido tiempo atrás. Por ello se puede entender que las necesidades y propuestas arquitectónicas de las cuales surgieron los ámbitos intermedios, fueron la simiente de la vivienda moderna yucateca, mismas que transmutaron las expresiones formales y definieron sus atributos y relaciones espaciales (Fig. 11).
Sin embargo no se puede obviar el hecho de la presencia y permanencia de algunos elementos espaciales observados en la casa vernácula yucateca, por lo que podría leerse un continuum en las tendencias de las propuestas espaciales, y si bien esta consideración podría ser arriesgada, resultaría también irónico negar la decantación de los múltiples elementos que primigeniamente la definieron y que en un sentido abstracto, quizás, veamos en nuestras viviendas contemporáneas. 


\section{BIBLIOGRAFÍA}

A. Moya Gutiérrez, "Historia, arquitectura y nación bajo el régimen de Porfirio Díaz. Ciudad de México 1876-1910" en Revista de Ciencias Sociales, vol. III-IV, núm. 117-118, Universidad de Costa Rica, Costa Rica, 2007.

G. Arana López, La vivienda de la burguesía en Mérida al cambio de siglo 1886-1916. La vida cotidiana en el ámbito privado, Gobierno del Estado de Yucatán-SEDECULTACONACULTA, Mérida, 2013

G. Arana López, La Vivienda de la Burguesía en Mérida al Cambio de Siglo (1886-1916). La vida cotidiana en el ámbito privado, tesis que para optar para el grado de Doctor en Arquitectura se presentó, Universidad Michoacana de San Nicolás de Hidalgo, Morelia, 2011.

J. López García, Protomodernidad arquitectónica en Aguascalientes (1884-1920), Universidad Autónoma de Aguascalientes, México, 2007.

R. Vargas Salguero, Historia de la Teoría de la Arquitectura: el Porfirismo, UAM-Xochimilco, México, 1989.

G. Arana López, "La fuerza de la memoria y la búsqueda de la modernidad. De la vivienda porfirista a la vida cotidiana en la posrevolución, 1925-1940" en María Elena Torres (coord.) Enfoque para una crítica del modelo de expansión urbana de la ciudad de Mérida, Yucatán. Las áreas habitacionales del primer medio del siglo XX, FAUADY, Mérida, en prensa.

G. Arana López, "Espacios y Objetos en la Vivienda. Historias del Habitar en Mérida, 1900-1940" en Laura Alarcón y Estrellita García (coords.) Cambios Sociales y construcción de imaginarios en el siglo XX, El Colegio de Jalisco, Guadalajara, 2013.

E. Ayala Alonso, La Casa de la Ciudad de México: evolución y transformaciones, CONACULTA, México, 1996.

E. Ayala Alonso, Habitar la Casa: Historia, actualidad y prospectiva, UAM-XOCH, México, 2010.

P. Gonzalbo Aizpuru (coord.), Historia de la vida cotidiana en México, El Colegio de México-Fondo de Cultura Económica, México, 2004.

D. De Landa, Relación de las cosas de Yucatán, Porrúa, México, 1982

L. Tello Peón, "La vivienda en Yucatán, su espacialidad y esencia" en Cuadernos de arquitectura no. 5, FAUADY, Mérida, 1992.

M. Pacheco León, Tipología de la Vivienda Colonial en Mérida en los Siglos XVI y XVII en Cuadernos de arquitectura no. 11-12, FAUADY, Mérida, 1999.

M. Lapointe, Historia de Yucatán: siglos XIX-XX, UADY, Mérida, 2008.

J. Ortiz Gaitán, "Casa, vestido y sustento. Cultura material en anuncios de la prensa ilustrada (1894-1939)" en Pilar Gonzalbo (dir.), Aurelio de los Reyes (coord.). Historia de la vida cotidiana en México. Vol. v. T. 2, El Colegio de México-FCE, México, 2006.

E. González Canto, Arquitectura Residencial en Mérida, tesis que para optar el grado de Maestro en arquitectura se presentó, FAUADY, Mérida, 2001. 


\section{NOTAS}

${ }^{1}$ Entre otros documentos, se recomienda revisar el trabajo Arquitectura, historia y nación bajo el régimen de Porfirio Díaz de Arnaldo Moya Gutiérrez. En el mencionado trabajo, se plantea que la arquitectura, fue empleada como un discurso pedagógico cívico, en aras de crear un renovado carácter nacional y moderno.

2 También conocido como sisal, siendo una materia prima empleada principalmente para hacer cuerdas. Por otra parte, la región conocida como sureste del México -aunque realmente se encuentra al este del centro de la república e incluso al norte de la ciudad capital- se puede considerar como una región lejana geográfica y circunstancialmente del resto de la república mexicana. Es una región en donde se habla, se come, se viste y en general se vive de forma diferente al resto de la nación al tener una cultura de origen prehispánico viva e hibridada en la contemporaneidad, lo que ha creado un ámbito plagado de tradiciones producto del mestizaje entre lo maya y lo español. Su ámbito natural se caracteriza por sus altas temperaturas, inexistente agua superficial, tierra calcárea e infértil así como grandes costas y considerables extensiones de selva baja. Históricamente ha vivido sus propias luchas sociales, cambios políticos y circunstancias culturales paralelamente a aquello que ocurría en el resto de la república mexicana.

3 A mediados de la década de 1880, el régimen de Díaz apostó por el surgimiento de una historia nacional integradora y conciliadora que junto con la enseñanza de la historia nacional se desarrolló un programa de transformación urbana de la ciudad de México y de una arquitectura emblemática, entendiéndose por esta, la razón artística que comprende los atributos de la nación vaciados en el canon arquitectónico. A. Moya Gutiérrez, "Historia, arquitectura y nación bajo el régimen de Porfirio Díaz. Ciudad de México 1876-1910" en Revista de Ciencias Sociales, vol. IIIIV, num. 117-118, Universidad de Costa Rica, Costa Rica, 2007, p. 160.

${ }^{4}$ En relación a la construcción de vivienda en el porfirismo y sobre las ge- neralidades de la vivienda en el mismo período ver G. Arana López, La vivienda de la burguesía en Mérida al cambio de siglo 1886-1916. La vida cotidiana en el ámbito privado, Gobierno del Estado de Yucatán-SEDECULTA-CONACULTA, Mérida, 2013, págs. 15-34.

${ }^{5}$ El Paseo de Montejo se llegó a considerar como el corredor más logrado del porfirismo en la región e incluso como un paradigma del régimen. En su diseño se integraron los conceptos de belleza urbana francesa, de higiene y de vínculo con la naturaleza. Para su edificación se emplearon nuevas técnicas constructivas concluyéndose los trabajos en el año de 1904. G. Arana López, La Vivienda de la Burguesía en Mérida al Cambio de Siglo (1886-1916). La vida cotidiana en el ámbito privado, tesis que para optar para el grado de Doctor en Arquitectura se presentó, Universidad Michoacana de San Nicolás de Hidalgo, Morelia, 2011, p. 84.

${ }^{6}$ Sobre el Paseo de Montejo se han publicado tanto monografías románticas y libros de imágenes, como críticas derivadas de su origen elitico-burgués. Entre estos documentos se encuentran: E. Tello, Monografía del Paseo de Montejo, una avenida metida en la entraña del pueblo yucateco. Ayuntamiento de Mérida, Mérida, 1980, C. Cámara, Cronología histórica y arquitectónica del Paseo de Montejo. Ayuntamiento de Mérida, Mérida, 2001 y C. Cámara, Las casonas del Paseo de Montejo, Megamedia, Mérida, 2009, entre otros.

7 Sobre el desarrollo de la vivienda, su caracterización y particularidades consultar: G. Arana López, La Vivienda de la Burguesía en Mérida al Cambio de Siglo (1886-1916). La vida cotidiana en el ámbito privado, tesis que para optar para el grado de Doctor en Arquitectura se presentó, Universidad Michoacana de San Nicolás de Hidalgo, Morelia, 2011.

${ }^{8}$ Estos ámbitos, si bien devienen de lenguajes arquitectónicos externos a la región, se puede considerar que definieron a la arquitectura mexicana desde su uso e implementación en las últimas décadas del siglo XIX. Algunos autores como J. López García, Protomodernidad arquitectónica en Aguascalientes (1884-1920), Universidad
Autónoma de Aguascalientes, México, 2007 y R. Vargas Salguero, Historia de la Teoría de la Arquitectura: el Porfirismo, UAM-Xochimilco, México, 1989 mediante análisis de casos de otras partes de la república mexicana llegan a esta conclusión, aunque, quizás el término "protomodernidad arquitectónica" empleado por López García pudiera no ser del todo exacto si nos referimos exclusivamente a las viviendas, ya que si se habla de una reconformación espacial y funcional en el interior de las mismas, esta transformación debería de ser considerada como modernidad plena y además sedimento esencial para los futuros planteamientos arquitectónicos. Esta argumentación se encuentra basada y fundamentada en el documento G. Arana López, "La fuerza de la memoria y la búsqueda de la modernidad. De la vivienda porfirista a la vida cotidiana en la posrevolución, 1925-1940" en María Elena Torres (coord.) Enfoque para una crítica del modelo de expansión urbana de la ciudad de Mérida, Yucatán. Las áreas habitacionales del primer medio del siglo XX, FAUADY, Mérida en prensa.

${ }^{9}$ Si bien el período de gobierno de Porfirio Díaz inició en el año de 1876 y concluyó en 1911, la temporalidad considerada para efecto de este trabajo se planteó de 1886 hasta 1916, ya que a partir de un análisis de las plantas arquitectónicas correspondientes a una muestra de alrededor de 200 viviendas se observaron cambios en la espacialidad de las mismas en esos años. Específicamente hasta antes de 1886 se mantenían las propuestas espaciales virreinales construyendo crujías simples alineadas al paramento y a partir de 1916 se empezaron a observar transformaciones espaciales sobre todo en relación a la compartimentación y funcionalización espacial. N. del A. Este tema se encuentra desarrollado en $\mathrm{G}$. Arana López, "Espacios y Objetos en la Vivienda. Historias del Habitar en Mérida, 1900-1940" en Laura Alarcón y Estrellita García (coords.) Cambios Sociales y construcción de imaginarios en el siglo XX, El Colegio de Jalisco, Guadalajara, 2013.

${ }_{10}$ En el mencionado trabajo, la investigación se abordó tanto cuantitativa como cualitativamente. En el 
primero de los casos se privilegiaron los espacios recurrentes, las dimensiones, los desplazamientos y las articulaciones funcionales, mientras que en la segunda parte de la investigación se abordó la vida cotidiana desarrollada en su interior, haciendo énfasis en el estudio de las relaciones entre el espacio contenedor y su contenido. G. Arana López, La Vivienda de la Burguesía en Mérida al Cambio de Siglo (1886-1916). La vida cotidiana en el ámbito privado, tesis que para optar para el grado de Doctor en Arquitectura se presentó, Universidad Michoacana de San Nicolás de Hidalgo, Morelia, 2011.

${ }^{11}$ G. Arana López, "La fuerza de la memoria y la búsqueda de la modernidad. De la vivienda porfirista a la vida cotidiana en la posrevolución, 19251940" en María Elena Torres (coord.) Enfoque para una crítica del modelo de expansión urbana de la ciudad de Mérida, Yucatán. Las áreas habitacionales del primer medio del siglo XX, FAUADY, Mérida, en prensa.

12 Entre los trabajos que destacan en relación a la vivienda y su vínculo con los cambios sociales, culturales y económicos en México se encuentran el de E. Ayala Alonso, La Casa de la Ciudad de México: evolución y transformaciones, CONACULTA, México, 1996 y del mismo autor Habitar la Casa: Historia, actualidad y prospectiva, UAM-XOCH, México, 2010, así como numerosos capítulos localizados en la colección P. Gonzalbo Aizpuru (coord.), Historia de la vida cotidiana en México, El Colegio de MéxicoFondo de Cultura Económica, México, 2004, por mencionar algunos.

${ }^{13}$ La Relación de las Cosas de Yucatán de Fray Diego de Landa, fue escrito originalmente en el año de 1566 después del Acto de Fe de Maní de 1562, capítulo final del proceso inquisitorial iniciado por el mismo Landa y en donde se quemaron sin número de imágenes de culto, objetos sagrados y códices de la cultura maya.

${ }^{14}$ D. De Landa, Relación de las cosas de Yucatán, Porrúa, México, 1982, p. 34 y 35 .

${ }^{15}$ Este está delimitado por una albarrada: muro bajo hecho con piedra sin mortero y regularmente pintado con cal. Este muro se empezó a edificar por imposición española, con el objeto de controlar el territorio.

16 Conformado por un $70 \%$ de espacios abiertos, $20 \%$ de cerrados y $10 \%$ de semiabiertos. L. Tello Peón, "La vivienda en Yucatán, su espacialidad y esencia" en Cuadernos de arquitectura no. 5, FAUADY, Mérida, 1992, p. 8.

${ }^{17}$ G. Arana López, La Vivienda de la Burguesía en Mérida al Cambio de Siglo (1886-1916). La vida cotidiana en el ámbito privado, tesis que para optar para el grado de Doctor en Arquitectura se presentó, Universidad Michoacana de San Nicolás de Hidalgo, Morelia, 2011, p. 148.

${ }^{18}$ La información más antigua localizada referente al año de 1579 es la de Martín Palomar, en la Relación de Mérida. En lo que se refiere a la forma y edificio de las casas y los materiales que hay para edificarlas dice: "... la forma de las casas de los españoles desta (sic) tierra es de aposentos bajos por el calor que haze (sic) y por gozar de alguna frescura y humedad, las casas son de piedra de mampostería, cubiertas de azotea o terrado, porque los tejados no se tienen por tan buenos...", mientras que Antonio de Ciudad Real en 1588 relataba "...las casas casi todas son de cal y canto, y de piedra y barro, con sus azoteas, aunque algunas hay cubiertas de teja, y otras (pero pocas) de paja; moran también en los arrabales muchos indios, así de los mexicanos que vivieron con los españoles cuando la conquista, como de los naturales de la tierra que han sido criados y conocidos". M. Pacheco León, Tipología de la Vivienda Colonial en Mérida en los Siglos XVI y XVII en Cuadernos de arquitectura no. 11-12, FAUADY, Mérida, 1999, p. 249.

${ }^{19}$ Estas paredes construidas con muy pocos vanos de sección reducida y proporción 1: 2 se abrían al exterior sólo para permitir la entrada de luz y ventilación necesarios para el confort. N. del A Las viviendas del siglo XVI, mantuvieron en planta un esquema en forma de "L" aunque es de suponer que la primera crujía que se construyó fue la paralela a la calle. Sin embargo lo que no se ha podido identificar claramente es el número de locales ni su composición formal en fachada, debido a los múltiples cambios que los edificios han sufrido y presentan actualmente. M. Pacheco León, Tipología de la Vivienda Colonial en Mérida en los Siglos XVI y $\mathrm{XVII}$ en Cuadernos de arquitectura no. 11-12, FAUADY, Mérida, 1999, p. 249.

${ }^{20}$ G. Arana López, La Vivienda de la Burguesía en Mérida al Cambio de Siglo (1886-1916). La vida cotidiana en el ámbito privado, tesis que para optar para el grado de Doctor en Arquitectura se presentó, Universidad Michoacana de San Nicolás de Hidalgo, Morelia, 2011, p. 150.

${ }^{21}$ Los jardines delanteros tenían una profundidad que oscilaba entre los tres y los doce metros. Solo unas cuantas casas tenían un magnífico jardín delantero de unos cuarenta metros, con un acceso tanto peatonal como vehicular flanqueado por árboles frutales y palmeras en medio de extensas áreas de césped. G. Arana López, La Vivienda de la Burguesía en Mérida al Cambio de Siglo (1886-1916). La vida cotidiana en el ámbito privado, tesis que para optar para el grado de Doctor en Arquitectura se presentó, Universidad Michoacana de San Nicolás de Hidalgo, Morelia, 2011, p. 155.

${ }^{22}$ El zaguán es la primer área que encontramos al acceder a la vivienda ya sea en vehículo de tracción animal o a pie; elemento de transición entre la calle o espacio urbano y el privado, generalmente sirve de vestíbulo al patio central, se localiza dentro del esquema general de la planta en un extremo o ligeramente desplazado. Sus dimensiones pueden variar en el ancho aunque generalmente son de 6 varas, y una altura aproximada de 5.5 varas. Los pisos de los zaguanes se componían de baldosas de piedra labrada, asentadas directamente sobre tierra apisonada, posiblemente su uso generalizado se debió a la resistencia que este material tiene y a su abundancia en la región. M. Pacheco León, Tipología de la Vivienda Colonial en Mérida en los Siglos XVI y $\mathrm{XVII}$ en Cuadernos de arquitectura no. 11-12, FAUADY, Mérida, 1999, p. 250.

${ }^{23}$ M. Pacheco León, Tipología de la Vivienda Colonial en Mérida en los Siglos XVI y XVII en Cuadernos de arquitectura no. 11-12, FAUADY, Mérida, 1999, p. 250. 
${ }^{24}$ Las propuestas espaciales y funcionales características del porfirismo se modificaron, al grado tal que estas pueden llegar a ser consideradas como la base experimental que culminaría en las expresiones arquitectónicas racionalistas, mismas que fueron partícipes de la construcción de imágenes domésticas reconocibles hasta la actualidad en la región.

${ }^{25}$ El proceso de modernización de las viviendas se expresó en sus propuestas formales, en las reconfiguraciones funcionales y más que nada, en la definición integral de cada uno de los espacios.

${ }^{26}$ En la segunda década del siglo $X X$, se publicó una orden en donde se indicaba que los propietarios de viviendas y demás fincas urbanas debían de colocar rejas u otros elementos que delimitaran las propiedades, en aras de mantener una adecuada imagen urbana.

${ }^{27}$ Poco a poco la sociedad cambió, sobre todo debido a que la oligarquía henequenera perdió el poder gubernamental de la región desatándose un fuerte debate sociopolítico en el cual se incluyó una contundente óptica socialista. Así, ante el debilitamiento de las altas esferas de la sociedad se propició que individuos pertenecientes a estratos más bajos socialmente ascendieran vertiginosamente.

Una vez sobrellevada la crisis revolucionaria, los nuevos tiempos eran propicios para la restructuración de las redes sociales, en donde lo secular y lo religioso se amalgamaban, al mismo tiempo que se iniciaba el intrincado tejido social resultado de la convivencia entre los resabios de la élite porfirista y la cada vez más poderosa clase política y militar revolucionaria. G. Arana López, "Espacios y Objetos en la Vivienda. Historias del Habitar en Mérida, 1900-1940" en Laura Alarcón y Estrellita García (coords.) Cambios Sociales y construcción de imaginarios en el siglo $X X$, El Colegio de Jalisco, Guadalajara, 2013, M. Lapointe, Historia de Yucatán: siglos XIX-XX, UADY, Mérida, 2008. p. 291 yJ. Ortiz Gaitán, "Casa, vestido y sustento. Cultura material en anuncios de la prensa ilustrada (18941939)" en Pilar Gonzalbo (dir.), Aurelio de los Reyes (coord.). Historia de la vida cotidiana en México. Vol. v. T. 2, El Colegio de México-FCE, México, 2006, p. 118.

${ }^{28}$ G. Arana López, "La fuerza de la memoria y la búsqueda de la modernidad. De la vivienda porfirista a la vida cotidiana en la posrevolución, 19251940" en María Elena Torres (coord.) Enfoque para una crítica del modelo de expansión urbana de la ciudad de Mérida, Yucatán. Las áreas habitacionales del primer medio del siglo XX, FAUADY, Mérida, en prensa.

${ }^{29}$ E. González Canto, Arquitectura Residencial en Mérida, tesis que para optar el grado de Maestro en arquitectura se presentó, FAUADY, Mérida, 2001. 